\title{
УПРАВЛЕНИЕ МАТЕРИАЛЬНО-ТЕХНИЧЕСКИМ ОБЕСПЕЧЕНИЕМ ПИЩЕВЫХ ПРОИЗВОДСТВ В СОВРЕМЕННЫХ УСЛОВИЯХ ХОЗЯЙСТВОВАНИЯ
}

\author{
(c) 2019 Крихели Михаил Давидович \\ аспирант кафедры менеджмента и маркетинга \\ Всероссийская академия внешней торговли, Россия, Москва
}

Статья посвящена рассмотрению современных тенденций в управлении материально-техническим обеспечением пищевых производств, позволяющих формировать добавленную стоимость на предприятии. Отдельный акцент сделан на моделях управления материально-техническим обеспечением. Также обоснована необходимость использования логистического подхода и сорсинга в управлении запасами. Особое внимание уделено влиянию материально-технического обеспечения на величину добавленной стоимости в пищевом производстве, направлениям и факторам ее увеличения.

Ключевые слова: материально-техническое обеспечение, пищевая промышленность, запасы, логистика, добавочная стоимость, сорсинг.

В современных чрезвычайно динамичных условиях жесткой конкуренции успешное функционирование и развитие предприятий пищевой промышленности существенно зависит от качества, скорости, надежности и эффективности их материально-технического обеспечения. Трансформация производственных отношений, изменение организационно-правовых форм и характера взаимосвязей хозяйствующих субъектов в экономической системе являются главными детерминантами процесса материально-технического обеспечения пищевых производств [1].

Радикальные изменения, которые обусловлены рыночными преобразованиями в экономике, повлекли за собой превращение материально-технического обеспечения в децентрализованную саморегулируемую систему, опирающуюся на спрос, предложение, цену и конкуренцию. Характер этих изменений обусловливает необходимость применения новых подходов к решению задач управления материально-техническим обеспечением.

Поэтому особого внимания требуют проблемы организации комплексного оперативного управления и рационального функционирования системы материально-технического обеспечения предприятия. Анализ научных работ показывает, что сегодня в качестве объектов исследования рассматриваются только отдельные компоненты обеспечивающей подсистемы (организация складского хозяйства, информационное наполнение, оптимизация складских запасов и затрат материалов и т.п.), тогда как недостаточно изученными остаются вопросы управления и организации новых и эффективных каналов товаропроводящей сети при закупках материальных ресурсов.

С целью повышения эффективности управления материально-техническим обеспечением необходимо решать вопросы улучшения планирования, учета и использования материально-технических ресурсов, обеспечения ритмичности поставок, контроля и реализации, нормирования запасов, усовершенствования системы складского хозяйства и т.д. [2].

В условиях обеспечения необходимыми материально-техническими ресурсами по справедливым ценам предприятий пищевой промышленности появляется возможность производить конкурентоспособную продукцию, что значительно увеличивает величину добавленной стоимости.

Таким образом, учитывая вышеизложенное, задачи, которые ставятся перед службой материально-технического обеспечения, необходимо пересмотреть в соответствии с условиями, в которых функционируют современные пищевые предприятия, что обуславливает актуальность темы исследования, определяет его концептуальную платформу на научный инструментарий познания.

Большой научный вклад в исследование проблем управления материально-техническим обеспечением промышленных предприятий, в целом, и пищевых, частности, в современных условиях развития экономических систем внесли: Н.В. Краснокутская, О.Е. Кузьмин, В.Е. Моска- 
люк, Г.М. Тарасюк, Л.И. Шваб и др.

Вместе с тем, не уменьшая значение научных достижений, указанных ученых, можно утверждать, что в современных работах не нашли достаточного отражения достаточно важные аспекты материально-технического обеспечения предприятий. В частности, необходимо более подробно остановиться на проблемах, возникающих при интегрированном управлении материально-техническим обеспечением пищевого производства. Существует также потребность в изучении новых подходов к организации материально-технического обеспечения предприятий на основе логистики и сорсинга.

Таким образом, с учетом вышеизложенного, цель статьи заключается в определении современных особенностей управления материально-техническим обеспечением пищевых производств и его влиянии на формирование добавленной стоимости.

Материально-техническое обеспечение предприятия - это процесс обеспечения производственной системы материально-техническими ценностями - производственными фондами - и управления движением материальных ресурсов от поставщика до конечного потребителя [3].

Управление материально-техническим обеспечением предприятия предусматривает выполнение всех функций, присущих управлению как виду деятельности:

- постановка задачи - включает накопление информации о состоянии материальных ресурсов предприятия, оценку материалоемкости производства и его потребности сырье, полуфабрикатах, проведение мониторинга имеющихся ресурсов и сырьевого рынка потенциальных поставщиков, планирование потребности в ресурcax;

- реализация поставленной задачи - формирование окончательного решения о развитии сырьевой базы предприятия, организация снабжения ресурсами, управление материально-техническими запасами;

- контроль за эффективностью формирования и использования материально-технических ресурсов во всех звеньях производственной системы [4].

В мировой хозяйственной практике исторически сложились две модели материально-технического обеспечения пищевого производства, присущих различным общественно-экономическим формациям.

Первая формируется и функционирует в условиях планово-административной системы хозяйствования и основывается на государственном регулировании и централизации управления распределительными отношениями между отдельными производственными сферами пищевой промышленности.

Вторая система присуща странам с эффективно функционирующей рыночной экономикой и основывается она на экономической и хозяйственной самостоятельности всех участников товарно-денежных отношений по поводу свободного выбора партнеров, условий поставок, ценообразования, форм и сроков расчетов и т.д. Роль государства в данной системе сводится к созданию и контролю за соблюдением нормативно-правовой базы, регулирующей взаимоотношения между партнерами, и разработке индикативных (базовых) параметров стратегии развития отрасли на национальном и региональном уровнях в соответствии с экономическими законами и тенденциями развития экономики и общества.

Современный подход к управлению материально-техническим обеспечением требует рассмотрения материальных ресурсов предприятия в динамике как единого материального потока (см. рис. 1).

В процессе усовершенствования управле-

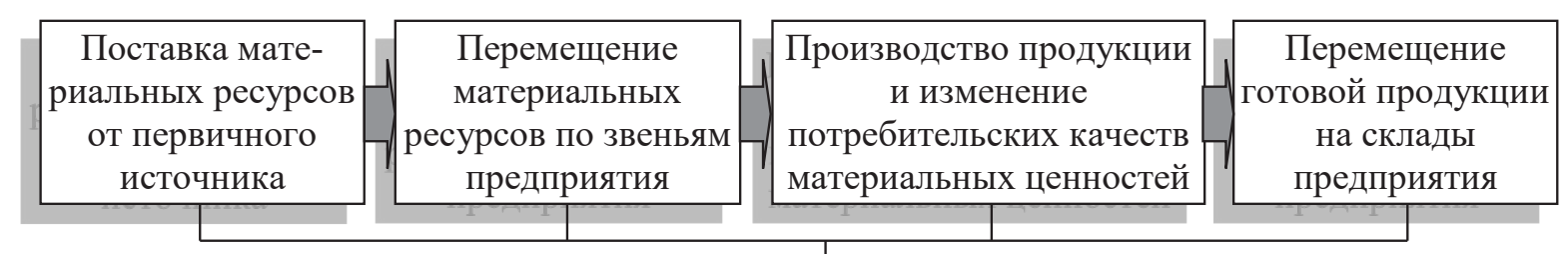

\section{ЕДИНЫЙ МАТЕРИАЛЬНЫЙ ПОТОК}

Совокупные расходы управления потоком 
ния материально-техническим обеспечением предприятия важно комплексное применение современных подходов. Установлено, что к таким подходам относится логистика, реинжиниринг и контроллинг, которые опираются на ряд одинаковых подходов и принципов, таких как процессный подход, системный подход, ориентация на заказчика, повышение ответственности работников всех уровней, взаимовыгодные отношения с поставщиками, информационное обеспечение в режиме реального времени, постоянное улучшение системы управления и организационной структуры. Они имеют единые цели, заключающиеся в повышении гибкости производства, улучшении качества продукции и снижении затрат на производство, отвечающее международным стандартам менеджмента качества ISO 9001: 2000 [6].

Анализ ключевых аспектов управления системой материально-технического обеспечения пищевых предприятий на практике показал, что повышение эффективности общей снабженческой цепи может быть достигнуто в результате исключения дублирования операций и непродуктивных затрат времени и ресурсов, то есть через внедрение организационных изменений, необходимых для реализации сквозного управления материальными потоками на основании концепции снижения общих затрат.

Итак, по мнению автора, отличительной чертой управления материально-техническим обеспечением предприятий пищевой промышленности на современном этапе является использование логистического подхода, который позволяет интегрировать поставщиков и потребителей, укреплять корпоративные связи, ориентируясь на стратегические потребности как самого предприятия, так и его деловых партнеров. Использование логистического подхода на пищевом производстве позволяет не только адаптировать предприятие к требованиям современного рынка, другими словами к быстрому выполнению заказов потребителей и точному соблюдению сроков поставки, но и обеспечить его опережающее развитие, а также эффективное использование стратегического ресурсного потенциала конкретного предприятия, повышение его конкурентоспособности (стратегический сорсинговий подход).

Стратегический сорсинг следует рассматривать как упорядоченный процесс, охватывающий все виды деятельности предприятия, входящих в полный цикл закупок, начиная от разработки спецификации продукта и заканчивая получением готовых товаров и услуг и их оплаты [7]. Главной целью стратегического сорсинга является обеспечение максимально высокой ценности, лучших услуг и низких общих расходов. При этом важно, чтобы он не просто приводил к снижению затрат, обеспечивая наличие необходимых товаров и услуг, но и повышал прибыль предприятия, а также создавал добавленную стоимость.

Как известно, добавленная стоимость - это стоимость продукции, за вычетом приобретенных промежуточных товаров [8]. То есть, при постоянной цене на готовый продукт, если стоимость купленных ресурсов будет меньше, то соответственно будет увеличиваться и величина добавленной стоимости. Однако это может быть только в том случае, если применяются прогрессивные ресурсосберегающие технологии производства продукции, при которых необходимые ресурсы используются рационально, а производство продукции увеличивается. Иными словами, при таких технологиях уменьшаются удельные расходы.

Необходимость и целесообразность ориентирования в процессе управления материально-техническим обеспечением пищевых производств на создание добавленной стоимости заключается еще и в том, что на всех циклах производства продукции в цепочке создания добавленной стоимости можно достичь уменьшения стоимости готового продукта, снижая себестоимость единицы продукции. В свою очередь, уменьшение стоимости готового продукта позволит увеличить прибыль.

Надлежащее обеспечение материально-техническими ресурсами позволит диверсифицировать производство и нарастить выпуск необходимой продукции. Например, ученые отмечают, что дефицит высококачественной пшеницы твердых сортов для хлебопекарного и макаронного производства некоторые государства покрывают импортным сырьем, генерируя тем самым финансовые и социальные потери от сокращения производственных циклов внутренних продовольственных рынков [9].

Схема влияния материально-технического обеспечения на величину добавленной стоимости в пищевом производстве показана на рис. 2. При этом в данной схеме для упрощения восприятия отдельно не выделена рента (арендная 
плата) и процент на привлеченный капитал, которые также являются элементами добавленной стоимости. Элементы добавленной стоимости рассматриваются с точки зрения собственности, поэтому и рента (арендная плата), и процент на привлеченный капитал представляют собой прибыль владельцев капитала. Конечно, указанные элементы добавленной стоимости входят в себестоимость продукции, но чем больше собственного капитала (меньше аренды и привлеченного капитала), тем больше прибыль предприятия.

Итак, при прочих равных условиях в процессе совершенствования управления материально-техническим обеспечением добавленная стоимость на пищевых предприятиях может увеличиваться, по мнению автора, в следующих случаях:

1. Уменьшение цены покупных материальных ресурсов (большее использование отечественного сырья, в том числе и дотирование цены государством), что влечет за собой снижение себестоимости продукции.

2. Рациональное использование материальных ресурсов за счет внедрения стратегического сорсинга и логистики, в также благодаря надлежащей организации производства, что приведет к снижению себестоимости продукции.

3. Обновление основных средств в соответствии с ресурсосберегающими технологиями. Это, конечно, приведет к общему увеличению себестоимости продукции (амортизационные отчисления являются статьей производственных затрат), но за счет повышения производительности оборудования себестоимость единицы продукции уменьшится.

4. Достаточное материально-техническое обеспечение пищевого комплекса позволит значительно увеличить как общую величину добавленной стоимости, так и по отдельности всех ее элементов. При этом, поддержка государства в этом вопросе должна быть определяющей.

Вместе с тем, учитывая тот факт, что в управлении материально-техническим обеспечением тесно переплетаются технические и экономические элементы, концепты стратегического планирования и прогнозирования, логистические оптимизационные задачи и новейшие информационные технологии, чрезвычайно актуальными являются высокие требования к качеству и профессионально-квалификационному уровню работников, занятых в сфере материально-технического обеспечения предприятия.

Процесс обеспечения ресурсами требует, чтобы персонал имел совершенные знания не только по вопросам организации поставок или способам формирования фондов, но и по вопросам организации производства, финансовых операций, правовых норм, рекламной деятельности, быстрой и правильной реакции на происходящее на товарном рынке изменения, а также навыки непрерывного поиска новых возможностей развития производства. Важно также хорошо знать своих клиентов-поставщиков, деловых партнеров в промышленности и в торговле, их интересы и прогнозировать поведение каждого в той или иной ситуации.

Менеджер по управлению материально-техническим обеспечением на пищевом предприятии должен не только уметь разрабатывать стратегическую систему прогнозного обеспечения необходимым материально-техническим оснащением и инструментами, которые требуются для нормального функционирования конкретного производства, но и обеспечивать дальнейшую системную оптимизацию функционирования всей логистической системы хозяйственного комплекса.

Таким образом, подводя итоги можно сделать следующие выводы.

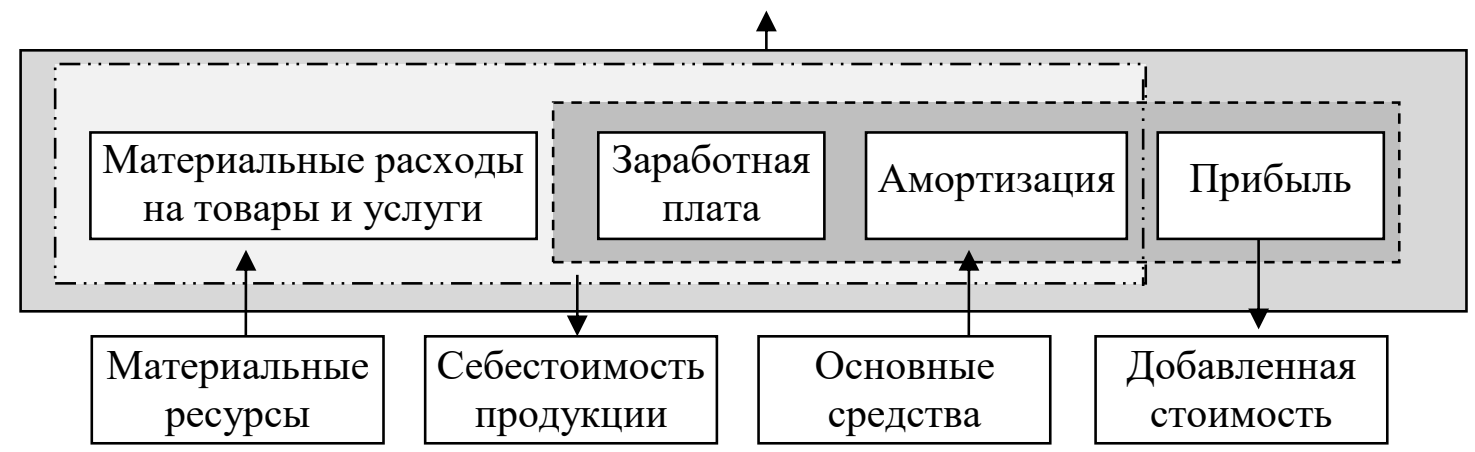

Puc. 2 Схема влияния материально-технического обеспечения на величину добавленной стоимости в пищевом производстве 
Рациональная организация материально-технического обеспечения и оптимальная система его управления в целом позволяют предприятию эффективно осуществлять производственную деятельность в условиях трансформационной экономики.

Факторами улучшения управления материально-техническим обеспечением пищевых производств являются:

- применение к процессам движения ресурсов совокупности научных подходов менеджмента;

- оптимизация формирования и использования ресурсов;

- усовершенствование состава продукции, сроков хранения;

- улучшение технологии изготовленной продукции;

- использование материалов с заранее заданными свойствами;

- выбор эффективных и оптимальных для данных условий форм и методов обеспечения ресурсами;

- стимулирование улучшения использова- ния ресурсов.

В процессе исследования установлено, что управление материально-техническим обеспечением пищевых производств сегодня должно ориентироваться на создание добавленной стоимости с использованием принципов и инструментов сорсинга - это является одной из основных задач функционирования предприятий в рыночных условиях. Такое целенаправленное управление позволит обеспечить альтернативность поставок наиболее ценных и стратегически важных материально-технических ресурсов, а также развитие вертикальной интеграции для совместного планирования цепочки поставок (информационное взаимодействие на основе ИТ-технологий в режиме реального времени).

Для реализации этой задачи целесообразно рассматривать систему материально-технического обеспечения как открытую, адаптивную, интегрированную, логистическую систему предприятия, которая функционирует на принципах сорсинга, обеспечивающего оптимальное соединение использования внутренних ресурсов предприятия с внешними источниками.

\section{Библиографический список}

1. Мисанова И.Н., Шатский Д.А. Политика управления запасами материально-технических ресурсов // Финансовая экономика.- 2018. - № 2.- С. 55-59.

2. Парфенова Е.Н., Авилова Ж.Н. Внедрение интегрированной системы управления как фактор развития промышленного предприятия // Вестник Белгородского государственного технологического университета им. В.Г. Шухова. - 2018. - № 7.- С. 143-146.

3. Нордин В.В. Процессный подход в материально-техническом обеспечении предприятий // Балтийский экономический журнал. - 2018. № 3.- С. 56-65.

4. Аслаханова С.А., Султанова М.А., Азиева М.З. Теоретические аспекты функционирования и управления материальными ресурсами на предприятии // ФГУ Science. - 2018. - № 1(11). - C. 15-18.

5. Бабенко И.В. Управление запасами как основа повышения эффективности системы материально-технического обеспечения предприятия // Экономика и предпринимательство. - 2017._№ 3-1.- С. $643-648$.

6. Чайковская Л.А., Дамдиндордж Б. Материально-техническое снабжение как подсистема логистики и его учетное обеспечение // Экономика и управление: проблемы, решения. - 2017. - Т. 1. - № 1.- С. $100-107$.

7. Песков Ю.В. Рассмотрение проблем и пути совершенствования процесса материально-технического обеспечения крупных производственных предприятий // NovaInfo.Ru. - 2017. - T. 1. - № 65.- C. 266-269.

8. Янина В.С., Гребнев Г.П. Направления по совершенствованию материально - технического обеспечения на предприятии // Экономика и социум.-2017.- № 3(34).-С. 2104-2107.

9. очкина М.В., Карамышев А.Н., Махмутов И.И., Федоров Д. Ф. Анализ многокритериальных методов выбора поставщиков // Экономика и предпринимательство._- 2017. - № 3-1(80). - С. 837-843. 